\title{
Research on How to Develop the Private School Well
}

\author{
Huang Jian \\ XiJing University \\ Xi'an 710123, China \\ 565200245@qq.com
}

\begin{abstract}
Practical experience shows that the development of state-owned private schools should follow the market rule. We believe that in order to obtain a broad education market, students must be regarded as the most important "serving object" of school education. All work of the school is a service chain, and the teacher will eventually provide a good and quality education to the students. To this end, we have implemented "service education". At the same time, state-owned private schools are a form of modern education, and their development should follow the education rule. Education should be consistent with children's growth pattern, meet the needs of children's development, and serve children's needs in the new era of learning-driven society. To this end, we have created a "high quality education" (high quality of the school, high school management, high school education), "three special" (students have special personality, teaching has a unique style, school has a school characteristics) as the external representation of the "quality education".
\end{abstract}

Keywords-Private education; Modern education; Quality education

\section{INTRODUCTION}

A. Follow the law of the development of private education, implement service education and create quality education.

Practical experience shows that the development of state run private schools should follow market rules. We believe that in order to obtain a broad education market, students must be regarded as the most important "service object" of school education. The work of the school constitutes a service chain, and ultimately a high-quality education is provided to students by teachers. To this end, we implemented "service education". At the same time, state-owned private schools are a form of modern education, and their development should follow the law of education. Education should conform to the law of children's growth, meet the needs of children's development, and serve for children to meet the social needs of lifelong education in the new era. To this end, we have created a "highquality education" with the external characteristics of "three high" (high quality of school education, high level of school management, high efficiency of school education), "three special" (students have their own characteristics, unique style of teaching, school running characteristics).

\section{B. Improve the running system of state run schools and give full play to the advantages of private schools.}

Compared with state-owned public schools, the schoolrunning system of state-owned private schools has the advantages of strong independence of the school-running subject, flexible operation mechanism, school-based management and organic integration of social human resources and material resources. Private schools have considerable autonomy in fund dispatching, institution setting, cadre appointment and removal, teacher appointment, curriculum setting, organization and command of teaching, quality and quantity of enrollment, financing and use of school funds, thus forming unique mechanism advantages. In the process of running schools, we must constantly improve the running system of state run schools and ensure the effective implementation of the advantages of the mechanism.

\section{Build a learning oriented school and a modern open} school culture, taking the road of connotative development

Inheriting the spirit of Peking University, inheriting the context of Peking University, introducing the advanced school-running ideas and management experience of Peking University Affiliated Secondary School, and integrating the high-quality educational resources of Peking University and Peking University Affiliated Secondary School are the needs of our school to give full play to its educational function and create the characteristics of modern school-running. We should continue to strive to establish an open school cultural environment with the main line of inheriting and expanding Peking University culture as its focus, with the fundamental purpose of developing subjectivity, promoting individuality and promoting the value of human life, promoting the integration of scientific spirit and humanistic spirit, and realizing the coordinated development of material culture, institutional culture and conceptual culture. Instead of opening the school culture system, we should build a common spiritual home for teachers and students. 
D. Persist in education innovation, publicize school individuality, and strive to form school running characteristics.

Innovation is the soul of school education and the source of inexhaustible power for the sustainable and leapfrog development of a school. The characteristics of the school are the external manifestation of the school-running idea, goal, strategy, achievement and level. As a state-owned private school, only by forming its own characteristics can it achieve sustainable and leapfrog development.

\section{E. Promote quality education in an all-round way, improve} the quality of education in an all-round way, improve the quality of students in an all-round way and fully explore the spirit of students'individuality with the guidance of educational research, the support of information technology and the breakthrough of curriculum reform.

In the course of curriculum implementation, our school takes educational scientific research as the guide, strengthens the scientific research of curriculum reform experiment, guides curriculum reform practice with educational scientific research achievements, integrates modern educational technology and subject curriculum in an all-round way based on information technology, and creates a brand-new education by applying modern information technology. In time and space, the optimization of curriculum structure, teaching process and teaching evaluation has been preliminarily realized, the solid promotion of quality education has been realized, the quality of education and the quality of students have been improved, and the sound personality of students has been cultivated.

\section{MEASURES}

\section{A. The implementation of people-oriented and scientific management, for the leaping and sustainable development of the school escort}

The school adheres to the management concept of "all for human development", implements the management strategy of "all for human development", establishes the incentive mechanism of "all for human development", and implements humanized and scientific school management. Schools strive to build a "democratic, united, concise and efficient" management team, practice the management ideas of "building schools by virtue, running schools by law, managing schools by democracy and developing schools by scientific research", adhere to the pragmatic style of leading cadres to drive teachers, cohere teachers with humanistic management, motivate teachers with scientific distribution mechanism and cultivate them. Training and practice develop teachers, strengthen school-based teaching and research and schoolbased training, and improve teachers'professional lifestyle. At the same time, school management should be carried out in accordance with the law of educational development, and objective systems and rules and regulations such as education and teaching, personnel and financial accounting, administrative logistics and student management should be established and perfected. The goal management, system management, psychological management and information management of all staff members should be implemented. A scientific and rational distribution system should be established and perfected to form a scientific one. Incentive mechanism to distribute wages, bonuses, benefits and allowances reasonably according to the nature of teachers'work, responsibility and performance is the key measure to fully mobilize teachers' enthusiasm, creativity, cohesion and development in the process of school management.

\section{B. Build a high-quality faculty to enhance the core competitiveness of the school.}

Our school always adheres to people-oriented principle and puts the development of teachers in the first place. We are committed to building a team of teachers with sufficient quantity, excellent quality, reasonable structure, erudite love for students and good teaching, improving teachers'professional competence, professional sentiment and personality quality, and letting every teacher in Nanshan Branch of Shenzhen, Middle School Affiliated to Peking University. There is happiness. School Summary

Building a high-quality faculty and improving the core competitiveness of the school.

Our school always adhere to the people-oriented, always put the development of teachers in the first place, to build a team of teachers with sufficient quantity, good quality, reasonable structure, learning and loving life, teaching good guidance, improving the professional ability, professional sentiment and personality quality of the teachers, and let every teacher in Shenzhen Nanshan Branch of Beijing University. There is a sense of happiness. The school has created a school culture that promotes the quality of human being and the value of life. It has nurtured a kind of inspiring and inspiring school spirit, and gradually formed a kind of core values that can help people to pursue and uphold, believe, adhere and implement. In the work and life of the school, the sense of pride in career development, the sense of achievement and the satisfaction of improving the quality of life have improved the core competitiveness of the school.

In order to meet the needs of innovative social development, according to the knowledge and technical characteristics of big data, the development direction of computer specialty is adjusted to "big data technology and application", and the preliminary exploration and adjustment of professional curriculum system are carried out. In order to meet the requirement of training applied talents, the specialty curriculum is optimized and integrated, the specialty orientation curriculum is highlighted, the specialty elective curriculum is expanded, and various levels of teaching methods are constructed, such as promoting the construction of the specialty "one teacher, one excellent" curriculum with high quality, fully tapping the advantages of "flipping classroom" and "mu class". In addition, curriculum design, introduction system of enterprise tutors, holidays comprehensive innovation practice training, school-enterprise joint training, and participation in enterprise research and development are arranged in the course. In order to meet the needs of innovative society for big data talents, the training of 
big data application ability is emphasized. Initially put forward new training programs for applied talents.

Through the above exploration, in 2016, the computer specialty of Information Engineering College began to implement a new talent training program, which planned to enroll two classes. In fact, the number of online students reached three classes, and the enrollment achieved good results. These reflect that it is absolutely necessary to further optimize the personnel training mode, constantly explore and reform the education and teaching methods in the era of big data, and improve the quality of training computer professionals. It also provides a new idea for further research of this project.

According to the development trend of big data and the demand for talents, the research method is to make full use of the existing teaching and scientific research platforms of the major, reduce the number of specialized courses appropriately, optimize the structure system of elective courses, and build a specialized course on the basis of students'access to sufficient public knowledge and Humanities knowledge. Basic courses and professional orientation courses are the main courses, professional elective courses and general courses are supplemented by computer professional curriculum system. The training requirements of meticulous specialized courses are put forward, and specific implementation goals are put forward. We should properly compress the in-class hours of specialized courses and elective courses, increase the hours of curriculum design, increase the assessment of practical links, and strengthen the training of applied talents. Increasing the number of professional elective courses makes students have a larger choice of space and promotes the development of students' personality. Combining with the new theories, new technologies and new methods in the field of big data processing, we should timely supplement the latest scientific and technological achievements in the curriculum design, increase the data processing courses or contents reflecting the era of big data, and improve students'ability to analyze and process big data using big data technology and professional tools.

\section{Updating curriculum contents to improve teaching quality}

It is proposed to strengthen the training of engineering practice ability into the teaching content, to increase some frontier knowledge of disciplines, and to integrate engineering application consciousness into the teaching. It is proposed to select some core courses of professional orientation for pilot projects and gradually extend them to other courses. Computer professional courses require higher practical operation ability. Teachers should combine theory with practice in the basic teaching process. They should transfer from theoretical teaching in the early stage to professional teaching in the later stage, from practical teaching in the main to theoretical explanation, and then to students'independent design and development according to the theme. At the same time, we should pay attention to interaction and communication between teachers and students. In theory teaching, teachers should let students understand the specific concepts, principles, basic methods and application fields of the course contents. Combining with examples and case teaching, they should mainly verify relevant theories, so that students can truly grasp theoretical knowledge and firmly remember from examples. In addition, they should interpolate new technologies related to big data. With the new method, students'learning enthusiasm is maintained, and they actively participate in teaching activities, so as to improve the whole teaching quality.

\section{Reforming practice teaching and constructing three level progressive training plan for application and innovation ability}

It is necessary to adjust the contents of innovative practice training, optimize contents, and establish a perfect innovative practice training curriculum system. In order to strengthen students'engineering practice ability and cultivate their practical ability, the contents of innovative practice training are determined, some old and backward verifiable experiments are deleted, and comprehensive and innovative contents with high scientific and technological content are introduced. Laboratories are opened to give full play to the use efficiency of existing experimental equipment, so as to ensure the safety of laboratories. On the premise of proving the basic experiment, more students are encouraged to go to the laboratory to carry out experiments, so as to improve the students'practical ability; standardized experimental assessment methods are designated, experimental results are reasonably assessed, basic experiments are taken as the main body of assessment, and students are assessed by the grading method combining basic part with full play part, so as to enable them to learn. The experimental ability of students has been evaluated more objectively. In the process of practical teaching, teachers make development themes for students in conjunction with professional curriculum experiments and curriculum design, and explain the matters needing attention and key techniques in the process of developing practice, actively guide and inspire students to think positively, carefully review experimental reports and listen to solutions, so as to avoid plagiarism and laziness among students. Elephants. Construct a three-level progressive training program of applied innovation ability with the main line of "cognitive practice, comprehensive practice and innovative practice" as shown in Figure 4. The project aims to cultivate students'engineering application ability from multiple perspectives in terms of cognitive ability, experimental ability, design ability and innovation ability.

\section{CONCLUSION}

Under the background of big data (such as medical and nursing big data, financial big data, agricultural big data, etc.), in order to solve the problem that the existing undergraduate training mode of computer science and technology specialty (hereinafter referred to as computer specialty) can not well meet the needs of new economy and new industry talents, this project draws lessons from CS2013 and other international countries. The latest curriculum system, through education

Of course, it is a complicated and arduous process that the orientation of running a school, the determination of the idea of running a running school, the setting of the curriculum, the equipment, the construction of the teacher team and the overall improvement of the quality of education and teaching. 
In this process, there are many links and steps. Every participant needs careful planning and careful operation.

\section{REFERENCE}

[1] Wen Dong Mao. On the non contradiction between public welfare and business viability of private education [J]. review of education in Peking University, 2004, 2 (1):43-48.

[2] Fanxianzuo. Financial and cost management of education [M]. Shanghai: East China Normal University press, 2004.

[3] Lv. Yan. The balance or profit distribution of private educational institutions. [J]. Journal of Henan College of Finance and Taxation, 2004, 18 (1): $26-27$.

[4] The law of the people's Republic of China on education promotion is adopted at the thirty-first session of the Standing Committee of the Ninth National People's Congress 2002.

[5] Ministry of education. Financial system for primary and secondary schools, 2013

[6] Tang Weibing, Fu Yuanhai, Wang Zhanxiang. And the transformation of economic growth mode of $[\mathrm{J}]$ technology innovation, economic research,.2014,7:31-42.

[7] Bai Junhong, Chiang Kai Shek. Collaborative innovation, spatial association and regional innovation performance [J], economic research.2015,7:174-187.

[8] Lutong, Party printing. Corporate governance and technological innovation: sub industry comparison [J], economic research.2014,6:115128.

[9] Li Wenlian, Xia Jian Ming. Based on "big data" business model innovation [J], China industrial economy.2013,5:83-95.

[10] Zhu Yongyong. Research on the integration of vocational education skills competition and practice teaching $[\mathrm{J}]$, higher engineering education research.2015,5:169-178. 